\title{
Nurses and midwives professional support increases with improved attitudes - design and effects of a longitudinal randomized controlled process-oriented intervention
}

\author{
Anette C Ekström ${ }^{*}$ and Stina Thorstensson
}

\begin{abstract}
Background: Becoming parents for the first time is challenging. Mothers need both social and professional support to handle these challenges. Professionals' attitudes affect quality of care and support. So to improve professional support, an intervention consisting of a process-oriented training was performed. Due to the positive results of the intervention there is a need to illuminate the methodological approach further. The overall aim was therefore to describe a methodological approach to improve and evaluate health care professionals' attitudes toward breastfeeding and parental support in order to improve quality of care in childbearing.

Methods: This study was a longitudinal randomized control intervention study, in which groups of mothers received care in childbearing from midwives and child health nurses. These health professionals had gone through a process-oriented training, or not. In order to improve attitudes of health professionals the training was based on evidence, practical skills and reflective processes (both private and professional experiences) in relation to breastfeeding and parental support. Included in the longitudinal study were health professionals from five intervention municipalities $n=36$ and health professionals from five control municipalities $n=45$. All mothers who fulfilled the inclusion criteria were consecutively identified from the hospital register and asked to participate in the study. Mothers who accepted to participate were included in the interventions group $(n=206)$ or control groups ( $n=162, n=172$ respectively) based on which municipality they belonged to.
\end{abstract}

Results: The results of the process-oriented training improved the professionals' attitudes toward breastfeeding and parental support. These improved attitudes in health professionals increased intervention-group mother's satisfaction with professional and social support. Intervention-group mother's relation to and feelings for their baby as well as breastfeeding was also improved.

Conclusion: These results stress the importance of professionals' attitude in quality of care during childbearing, as well as pointing to the possibility to improve professionals' attitudes with a process-oriented training.

Trial registration: Australian New Zealand Clinical Trials Registry (ANZCTR), trial registration: ACTRN12611000354987.

Keywords: Childbirth, Childbearing, Breastfeeding, Parental support, Interaction, Pedagogy, Professional support, Professional attitudes

\footnotetext{
* Correspondence: anette.ekstrom@his.se

School of health and education, University of Skövde, Post box 408, S 54128

Skövde, Sweden
} 


\section{Background}

To become parents for the first time is a major change of life event $[1,2]$. It involves the physiological endeavour of pregnancy, birth and breast-feeding, but also changes in social lives $[3,4]$. To handle these challenges mothers need both social and professional support [5, 6]. Support has been described as an interactive process that affects wellbeing and health of the individual [7]. Social support is offered within individuals own network and then working relationships and trust is required for support to be effective. Professional support, however, is directly available but limited by professional domain and knowledge, for example childbearing and midwifery [8]. So it is important to differentiate between social and professional support in research [9]. Care interventions with professional support should also aim to strengthen social support [10]. In childbearing, professional support from nurses and midwives is important for parents' childbirth experience [11-14]; for mother infant interaction [15-17] and for breastfeeding [18]. Health professionals' personal attitudes affect quality of care and support as well as their perception of the support they offer. This will affect professionals ability to meet patients' individual needs, however more research is needed [19]. So to achieve improved quality of care, a change of attitude among health care professionals is needed. To change attitudes an approach with both fact and reflection has been described [20] and reflection is essential for professionals' skills development [20, 21]. Therefore an intervention with a process-oriented training including evidence based lectures and reflection was performed to change health professionals' attitudes toward breastfeeding and parental support. This intervention resulted in health professionals attitudes becoming more facilitating and less regulating [22], mothers experienced improved professional support, improved selfreported relation to and feelings for the baby and breastfeeding $[15,17,23-28]$. Due to these positive results there is a need to illuminate the methodological approach further. The overall aim is therefore to describe a methodological approach to improve and evaluate health care professionals' attitudes toward breastfeeding and parental support in order to improve quality of care in childbearing.

\section{Methods}

\section{Design}

This was a longitudinal randomized control intervention study, in which groups of mothers received care in childbearing from antenatal midwives and child health nurses (here referred to as health professionals). The health professionals had gone through a process-oriented training in breastfeeding and parental support, or not. The group of health professionals that had not gone through the process-oriented training could be considered as the standard care group. The study design follows the Consort recommendations and it is registered in Australian New Zealand Clinical Trials Registry (ANZCTR), trial registration: ACTRN12611000354987. The study design is presented in Fig. 1.

\section{Setting}

The study was performed in a county in the southwest of Sweden, with 280,000 inhabitants, consisting of 13 municipalities with antenatal and child health centres and comprised of urban, suburban, and rural districts. Approximately 2500 births occurred annually at the two hospitals at this time period. Mothers and their partner would meet a midwife for pregnancy medical check-ups, parental education and support approximately eight to eleven times during pregnancy. Almost all mothers gave birth in hospital, and care in hospital was provided by midwives who were not previously known to the mothers. The average length of hospital stay was between six hours to seven days, and a child-health nurse made a home visit seven to ten days after the birth, and remained in contact until the baby was old enough to start school at six years of age. Visits to the child-health nurse included medical check-ups of the child and information/support in breast-feeding and parenting. Results from a mapping study showed mothers lacked information and support in breast-feeding and parenting [29].

\section{Intervention}

This intervention has two phases; the first phase was the process-oriented training to improve health professionals' attitudes and the second phase was evaluating whether health professionals improved attitudes had effect on breastfeeding, feeling and relation to the baby and mothers' experiences of support.

\section{Phase 1: The process-oriented training for midwives and child health nurses (health professionals) in breastfeeding and parental support}

First part Allocation of municipalities to intervention or control groups. Based on the findings of a baseline study $[29,30]$, the ten largest municipalities in the selected area were paired according to their sizes and duration of breastfeeding. For each pair of municipalities, one was then randomly designated to the five-municipality intervention group and one to the five-municipality control group. Then antenatal midwives and child health nurses were allocated to intervention or control depending on whether their work site had been selected as an intervention municipality or as a control municipality. In total 116 health professionals were asked to participate in the study [15, 17, 22-28]. A Breastfeeding Attitude Instrument was developed to measure breastfeeding 


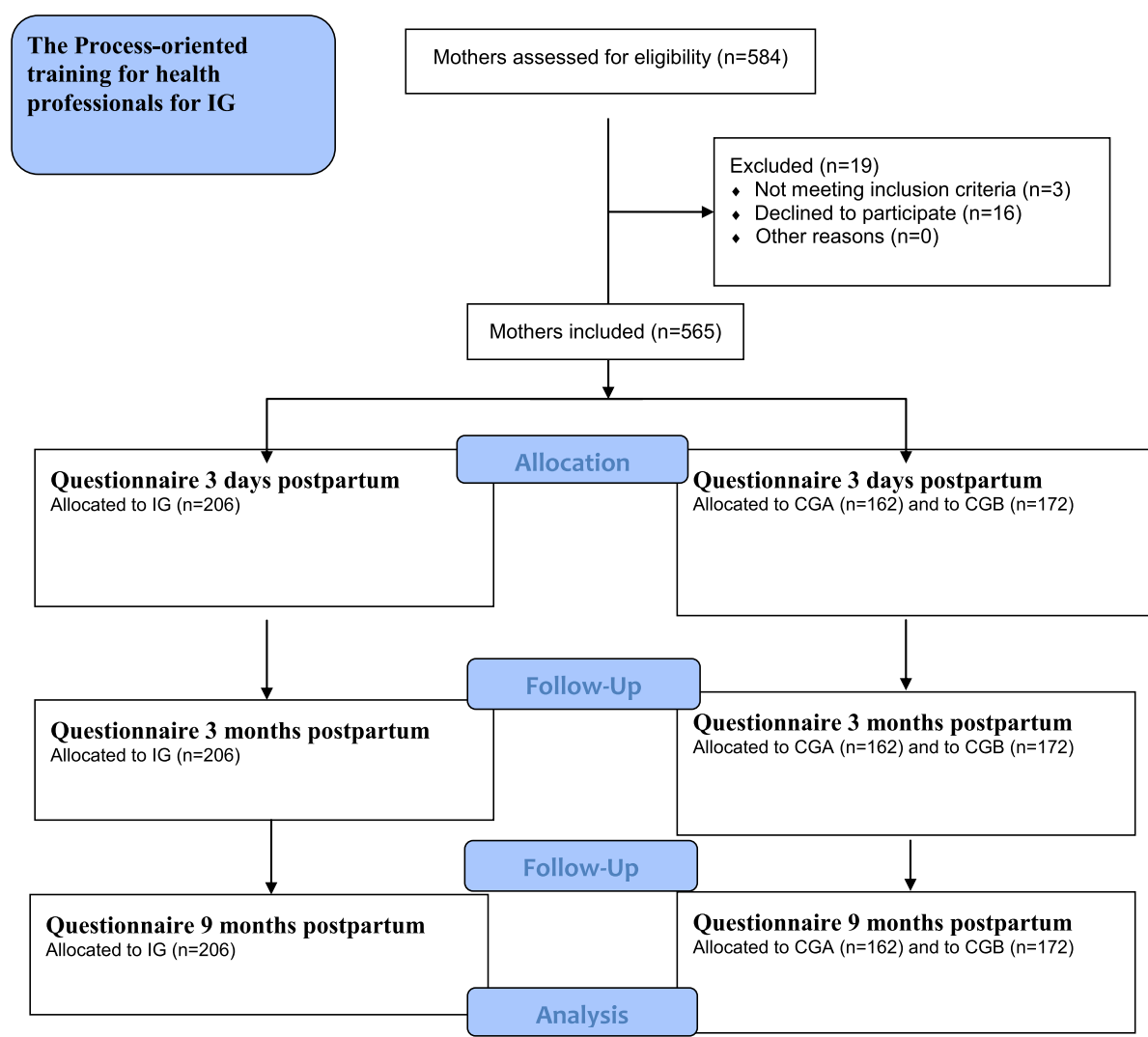

Fig. 1 Flow diagram of how mothers enrolled in the Intervention group (IG), Control Group A (CGA) and Control Group B (CGB)

attitudes in health care professionals $(n=168)$, Four attitude dimensions were identified by factor analysis [31].

Second part Thus, all antenatal midwives and child health nurses working at the randomised intervention municipalities accepted to participate in the study ( $n=$ 81). A process-oriented training [20] in breastfeeding and parental support was conducted for midwives and child health nurses (together referred to as 'health professionals' for the remainder of this report) from the intervention municipalities. Figure 1 describes flow diagram of included mothers, Fig. 2 demonstrates the process of the training and Appendix 1 describes the content of the process-oriented program. Health professionals' attitudes were evaluated with the breastfeeding attitude instrument, before, immediately after and one year after the process-oriented training [22].

Phase 2: Evaluation of effects for mothers of the processoriented training for health professionals

Mothers who were included in the study had either been cared for by health professionals in one of the five intervention municipalities or by health professionals in one of the five control municipalities. None of the mothers knew whether their antenatal midwife and child health nurse had gone through the process-oriented training (intervention groups) or not (control groups). During their stays at the delivery and maternity ward at the hospital, all the mothers met midwives who had not participated in the process-oriented training.
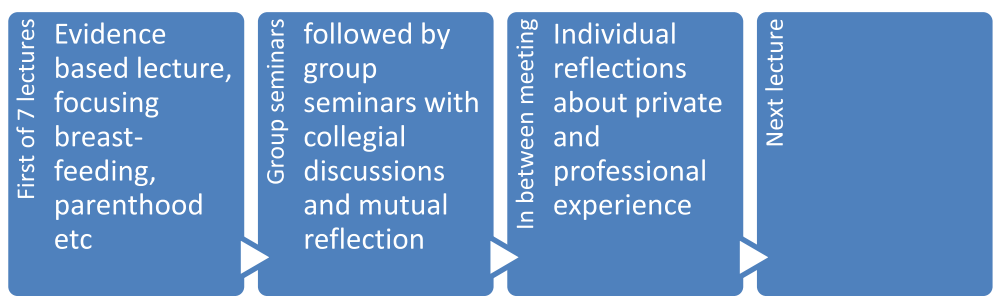

Fig. 2 The process of the training 
Inclusion criteria Mothers who were Swedish-speaking, healthy first-time mothers and who gave birth to single, healthy full-term babies delivered spontaneously, by vacuum extraction, or by Caesarean section were eligible.

Exclusion criteria Mothers who were first-time mothers and who had given birth to babies with malformations or life-threatening diseases, for example life-threatening illness such as very severe asphyxia, were excluded.

All mothers who fulfilled the inclusion criteria and had been cared for at the antenatal and child health clinics in the municipalities selected for this study were consecutively identified from the hospital register and asked to participate in the study $(n=584)$ (Fig. 1). Of those, 480 gave their informed consent to participate, which translates to a response rate of $82 \%$ (Table 1). Before the process-oriented training commenced and any effects of the intervention could be measured, data were collected for a baseline group called Control Group A (CGA, $\mathrm{n}=162)$. Data for Control Group B (CGB, $\mathrm{n}=$ 172) and Intervention Group (IG, $\mathrm{n}=206$ ) were collected simultaneously. This design allowed detection of changes over time and any spill over effects of the intervention. The same five municipalities provided the sample population for CGA and CGB. Sociodemographic and obstetric data for included mothers is presented in Table 2.

\section{Evaluation of health professionals improved attitudes effect for mothers}

Three questionnaires were developed about professional (MoPPS-scale) and social support, mothers' self-reported feelings for and relation to the baby (MIRF-scale) and breastfeeding. Maternity staff members distributed the first questionnaire to the mothers three days after birth. Follow-up questionnaires were posted to the mothers three months and nine months after birth (Fig. 1). Obstetric and demographic data were collected from birth records, and socio-demographic background data were collected with the first questionnaire (Table 2). The three questionnaires developed for this study were pilottested by 20 mothers for acceptability and face validity. In addition, an expert group of health professionals was consulted to establish content validity. A few minor corrections to the wording were made before the data collection began.

\section{Statistics}

For the statistical analyses of the data, we used the Statistical Package for the Social Sciences (SPSS) version 13, $14 \& 15$. Central measurements were presented as a mean $(\mathrm{M})$ and dispersion by standard deviation (SD). To test the differences between the groups, one-way ANOVAs and Tukey's HSD-test for post hoc comparisons were performed. Chi-square tests were performed on category data. Pearson's rank correlation was used to relate data on the ordinal level. In order to reduce the amount of data tested all items representing the mothers' relation to and feelings for the baby were entered into a principal component factor analysis using varimax rotation. A forward multiple linear regression analysis was performed to examine the impact of the obstetrical variables [32]. In one of the studies [17] Cohen's guidelines were used to calculate the effect sizes in order to interpret clinical change, and the effect was defined as small $(>0.20)$, moderate $(>0.50)$, or strong $(>0.80)[17$, 33]. $P$-values $\leq 0.05$ were considered significant [32].

\section{Ethical considerations}

We obtained ethical approval from the Ethical Review Board of Gothenburg (EPN) before any data collection began, register number L 188-99, L 005-98 and 40509. The head of the organization was given information about the study and gave us access to undertake this study. The participating first-time mothers were given written and oral information about the study, as well as information explaining that their participation was voluntary and that they could withdraw from the study at any time without having to provide a reason and without their care being affected.

\section{Results}

Effects of this intervention has been published in scientific journal and a book chapter (Table 3).

\section{Professionals' breastfeeding attitudes}

Effects of the process oriented training (Fig. 2 and Appendix 1) in relation to professionals' breastfeeding attitudes was measured with the breastfeeding attitude instrument [22] which can be used for accurate assessment of health professionals' breastfeeding attitudes. By means of factor analysis four factors were identified: the "Regulating" factor

Table 1 Response rate for all groups at 3 days, 3 months, and 9 months postpartum

\begin{tabular}{lllllllll}
\hline & IG $n=206$ & & \multicolumn{2}{l}{ CGA $n=162$} & \multicolumn{2}{l}{ CGB $n=172$} & Total $n=540$ & $p$ \\
\hline 3 days postpartum, $\mathrm{n}(\%)$ & 172 & $(84 \%)$ & 148 & $(91 \%)$ & 160 & $(93 \%)$ & $480(89 \%)$ & n.s \\
3 months postpartum, $\mathrm{n}(\%)$ & 145 & $(70 \%)$ & 126 & $(78 \%)$ & 132 & $(77 \%)$ & $403(74 \%)$ & n.s \\
9 months postpartum, $\mathrm{n}(\%)$ & 131 & $(64 \%)$ & 116 & $(72 \%)$ & 125 & $(73 \%)$ & $372(69 \%)$ & n.s \\
\hline
\end{tabular}

The intervention group (IG), Control Group A (CGA) and Control Group B (CGB) 
Table 2 Sociodemographic and obstetric data for mothers in all groups at three days after

\begin{tabular}{|c|c|c|c|c|c|c|}
\hline & IG 172 & & CGA 148 & & CGB 160 & \\
\hline Age in years ( $m$ and $S D)$ & 26.6 & $(4.5)$ & 27.2 & $(4.6)$ & 27.0 & $(5.0)$ \\
\hline Gestational weeks ( $m$ and SD) & 40.4 & $(1.4)$ & 40.5 & $(1.4)$ & 40.4 & $(1.4)$ \\
\hline \multicolumn{7}{|l|}{ Education } \\
\hline Compulsory school (\%) & 6 & (3\%) & 5 & (3\%) & 3 & $(2 \%)$ \\
\hline High school (\%) & 77 & $(37 \%)$ & 73 & $(45 \%)$ & 71 & $(41 \%)$ \\
\hline University (\%) & 74 & $(36 \%)$ & 55 & (34 \%) & 62 & $(36 \%)$ \\
\hline Other (\%) & 14 & $(7 \%)$ & 15 & (9\%) & 21 & $(12 \%)$ \\
\hline Missing & 35 & $(17 \%)$ & 14 & (9\%) & 15 & $(9 \%)$ \\
\hline \multicolumn{7}{|l|}{ Marital status } \\
\hline Cohabitation (3 days postpartum) & 125 & $(61 \%)$ & 102 & $(63 \%)$ & 118 & $(69 \%)$ \\
\hline Married & 42 & $(20 \%)$ & 43 & $(27 \%)$ & 38 & $(22 \%)$ \\
\hline Single & 3 & $(1.5 \%)$ & 2 & $(1 \%)$ & 2 & $(1 \%)$ \\
\hline Other & 1 & $(0.5 \%)$ & 3 & $(2 \%)$ & 2 & $(1 \%)$ \\
\hline Missing & 35 & $(17 \%)$ & 12 & $(7 \%)$ & 12 & $(7 \%)$ \\
\hline \multicolumn{7}{|l|}{ Obstetric data } \\
\hline Vaginal delivery (\%) & 146 & $(70 \%)$ & 120 & $(74 \%)$ & 129 & (75\%) \\
\hline Caesarean section (\%) & 32 & $(16 \%)$ & 22 & $(14 \%)$ & 31 & $(18 \%)$ \\
\hline Vacuum extraction/forceps (\%) & 28 & $(14 \%)$ & 20 & $(12 \%)$ & 12 & $(7 \%)$ \\
\hline
\end{tabular}

The intervention group (IG), Control Group A (CGA) and Control Group B (CGB)

Table 3 Overview of publications from the Intervention

\begin{tabular}{|c|c|c|c|c|}
\hline $\begin{array}{l}\text { Ref } \\
\mathrm{nr}\end{array}$ & Authors & Title & Journal & $\begin{array}{l}\text { Year } \\
\text { of publ }\end{array}$ \\
\hline 31 & $\begin{array}{l}\text { A.Ekström, A.Matthiesen, } \\
\text { A.Widström, E.Nissen }\end{array}$ & $\begin{array}{l}\text { Breastfeeding attitudes among counselling health professionals. } \\
\text { Development of an instrument to describe breastfeeding attitudes. }\end{array}$ & $\begin{array}{l}\text { Scandinavian Journal of Public } \\
\text { Health, 33(5), 353-359. }\end{array}$ & 2005 \\
\hline 22 & $\begin{array}{l}\text { A.Ekström, A.Matthiesen, } \\
\text { A.Widström, E.Nissen }\end{array}$ & $\begin{array}{l}\text { Process-oriented Training in Breastfeeding Alters Attitudes to } \\
\text { Breastfeeding in Health Professionals. }\end{array}$ & $\begin{array}{l}\text { Scand. J of Public Health, 33(6), } \\
424-431 .\end{array}$ & 2005 \\
\hline 28 & $\begin{array}{l}\text { A.Ekström, A.Matthiesen, } \\
\text { A.Widström, E.Nissen }\end{array}$ & $\begin{array}{l}\text { Does Continuity of Care by Well-Trained Breastfeeding Counselors } \\
\text { Improve a Mother's Perception of Support? }\end{array}$ & Birth, 33(2), 123-130 & 2006 \\
\hline 15 & A.Ekström, E.Nissen & $\begin{array}{l}\text { A mothers's feelings for her baby are strenghten by excellent } \\
\text { breastfeeding counseling and continuity of care. }\end{array}$ & Peadiatrics, 118(2), e309-e314. & 2006 \\
\hline 27 & A.Ekström, E.Nissen & $\begin{array}{l}\text { Process-Oriented Training in Breastfeeding Attitudes and Continuity } \\
\text { of Care Improve Mothers Perception of Support. }\end{array}$ & $\begin{array}{l}\text { Health Education Research Trends. } \\
\text { Nova Publishers. NY. }\end{array}$ & 2007 \\
\hline 25 & $\begin{array}{l}\text { A.Ekström, K.Guttke, M.Lenz, } \\
\text { E.Hertfelt Wahn }\end{array}$ & $\begin{array}{l}\text { Long term effects of professional breastfeeding support - An } \\
\text { intervention. }\end{array}$ & $\begin{array}{l}\text { International Journal of Nursing } \\
\text { and Midwifery, Vol. 3(8), pp. 109- } \\
117 .\end{array}$ & 2011 \\
\hline 26 & $\begin{array}{l}\text { A.Ekström, E.Kylberg } \\
\text { E.Nissen, }\end{array}$ & $\begin{array}{l}\text { A process-oriented breastfeeding training for health professionals } \\
\text { to promote breastfeeding. }\end{array}$ & $\begin{array}{l}\text { Breastfeeding Medicine. } 7(2), 85- \\
92 .\end{array}$ & 2012 \\
\hline 17 & $\begin{array}{l}\text { S.Thorstensson, E.Nissen, } \\
\text { A.Ekström }\end{array}$ & $\begin{array}{l}\text { Professional support in pregnancy influence maternal relation to } \\
\text { and feelings for the baby after Cesarean birth; an intervention } \\
\text { study. }\end{array}$ & Journal of Nursing \& Care 1:112. & 2012 \\
\hline 23 & $\begin{array}{l}\text { I.Blixt, L.B.Mårtensson, } \\
\text { A.Ekström }\end{array}$ & $\begin{array}{l}\text { Process-oriented training in breast feeding for health professionals } \\
\text { decreases breastfeeding challenges. }\end{array}$ & $\begin{array}{l}\text { International Breastfeeding Journal, } \\
9: 15\end{array}$ & 2014 \\
\hline 24 & $\begin{array}{l}\text { A.Ekström, H.Abrahamsson, } \\
\text { R-M.Eriksson L.B.Mårtensson, }\end{array}$ & $\begin{array}{l}\text { Women's use of nipple shields - its influences on breastfeeding } \\
\text { duration after a process oriented education for health professionals. }\end{array}$ & $\begin{array}{l}\text { Breastfeeding Medicine, 9(9), 458- } \\
466\end{array}$ & 2014 \\
\hline
\end{tabular}


focused on regulating mothers' breastfeeding management, the "Facilitating" factor focused on making it easy for mothers to manage their breastfeeding, the "Disempowering" factor focused on giving advice, disregarding the needs of the woman being counselled and the "Breastfeeding antipathy" factor focused on insufficient, basic, breastfeeding knowledge and aversive reactions to breastfeeding [22]. After one year, health professionals in the intervention group reduced their scores on the regulating scale $(p<0.001)$ and increased their scores on the facilitating scale [27] when compared with control group health professionals.

\section{Improved professional attitudes effect for mothers Mother's perception of professional support}

Overall, mothers in the IG reported more a positive perception of professional support, than mothers in the CG [28]. In addition, IG mothers with a caesarean birth reported more positive on professional support during pregnancy than CG mothers [17]. IG mothers also reported a more positive perception of professional support from staff at the labor and maternity ward than CG mothers [25], despite the fact that these professionals were not included in the process-oriented training. IG mothers reported improved professional support in preparation for the parental role and their partners were more active in parental support groups than CG mothers partners were. IG mothers also reported stronger social support from other parents than CG mothers did [28].

\section{Mother's feelings and relation to the baby}

As a result of improved professional support IG mothers reported stronger for feelings and relation to the baby than CG mothers did [15]. In addition, IG mothers with a caesarean birth also reported stronger for feelings and relation to the baby than CG mothers with a caesarean birth did [17].

\section{Positive influence in breast-feeding}

IG mothers reported improved breastfeeding support leading to earlier initiation, higher frequency of breastfeeding the first $24 \mathrm{~h}$ [25], less breast-milk substitute in the first week of life (without medical reasons) and introduction of breast milk substitutes after discharge from the hospital, were delayed in relation to CG group mothers [26]. In addition, IG mothers reported less breast-feeding challenges such as; experiencing insufficiency in breast-milk, the first three months after birth [23], despite the use of nipple shields or not [24]. IG mothers also reported longer breastfeeding duration than CG mothers did [15, 23-28].

\section{Discussion}

This article describes a methodological approach, a process-oriented training, which improved midwives and child health nurses attitudes toward breastfeeding and parental support. Improved attitudes in health professionals lead to mothers being more satisfied with professional support. In addition the improved professional support increased mothers feelings and relation to the baby, earlier initiation and higher frequency of breastfeeding the first $24 \mathrm{~h}$, less breast-milk substitute (without medical reasons), less breast-feeding challenge (despite the use of nipple shields) and as a result of these, longer breastfeeding duration.

These improved attitudes in health professionals tended to be stable over time and IG mothers reported more satisfaction with emotional and informative professional support during the first nine months after birth than CG mothers. In line with other research, quality of care is improved by enhancing health professionals' attitudes [34]. since health professionals attitudes influence their ability to meet individual needs of patients [21, 35]. In order to improve attitudes both fact and reflection is needed [20] which is essential for skills development in professional education $[20,21]$. This is in line with our result that a process-oriented training which integrated facts with reflections on both professional and personal level lead to improved professional attitudes.

In evaluation of the process-oriented training, health professionals described that they did not have adequate time available to pursue the education during working hours. They described that despite decision making heads expressed an interest in the training the health professionals experienced that they did not have reasonable conditions to pursue the course (unpublished data). This points to lack of understanding among heads of organizations that competent health professionals require reasonable conditions to develop good quality in health care [36]. Evidence based health care demand possibilities for health professionals to develop their abilities and knowledge during working hours. Heads of health care should not assume that midwives and nurses shall dedicate their free time for professional development.

IG mothers reported a more positive perception of professional support during childbearing as a result of the intervention. However, our results also highlight the fact that IG mothers reported more positive support from the professionals in the delivery ward and the maternity ward, despite the fact that these health professionals were not involved in the process-oriented training. Social and professional support is affected by earlier experiences of receiving support [7, 37], and positive memories of a situation influence a friendly approach in a similar situation [38]. It is possible that mothers who have had a more positive experience of 
support during antenatal care are more likely to have a positive perception of support from other health professionals as well. Mothers in the IG also reported improved professional support in preparation for the parental role and their partners were more active in parental support groups compared to CG mothers. This result is in line with other researchers that highlights professional support as important for parent's childbirth experience [11-14].

In addition results from our studies showed that improved professional support increased IG mother's feeling and relation to the baby, including IG mothers with caesarean birth who are particularly vulnerable. Mothers with caesarean birth are more likely to suffer from psychosocial health problems after childbirth [39-41], and they seem more self-oriented and less self-confident when caring for the baby two months after birth [40], which may negatively influence mother-infant interaction $[42,43]$. These results point to the importance of improving professional attitudes to improve support and quality of care for mothers and families in childbirth.

As a result of the process-oriented training mothers in the IG reported earlier initiation, higher frequency of breast-feeding the first $24 \mathrm{~h}$ [25], less breast-milk substitute (without medical reasons) [26], less breastfeeding challenge despite the use of nipple shields and as a result of these increased breastfeeding duration [24] compared to CG mothers. Our result is in line with other research showing that when health professionals receive breastfeeding education based on WHO guidelines, they feel more secure and experience an increased ability to support mothers with coherent, evidence-based counselling [44]. Other research shows that when caregivers have communication skills, their ability to empathize and find individual solutions increases, which reduces the risk that mothers perceive the advice as contradictory [45-47]. Mothers need to receive realistic, consistent and evidence-based information on breastfeeding [48] and a combination of group and individual counselling is more efficient for breast-feeding success [49]. Mothers with higher knowledge of breastfeeding also have more confidence in their ability to breastfeed [50].These results may affect mother's ability to manage their breastfeeding problems better, depending on whether the breastfeeding counselling was more suited to their needs and their life situation.

This longitudinal intervention method with two control groups (CGA data was collected before any effects of the intervention could be measured) was selected as being suitable for the study. This is a design suggested to measure possible spillover effects [51]. More differences were found when the IG was compared with the CGA than when the IG was compared with the CGB (where data were collected simultaneously with the IG).
These results show that changes also take place among controls when an intervention is being rolled out. In the professional network of midwives and child health nurses, knowledge and information are shared, which easily leads to spillover effects between intervention and control professionals. These results thus demonstrate the value of using a historic control group, which will provide a baseline against which to evaluate the spillover effect. Strength of the study was that the participating mothers did not know whether they encountered health professionals who had undergone the process-oriented training or not.

\section{Conclusion}

A methodological approach as a process-oriented training for midwives and child health nurses, improved their attitudes toward breastfeeding and parental support. In addition these improved attitudes increased IG mother's satisfaction with professional and social support as well as their relation to and feeling for the baby and breastfeeding. These results stress the importance of professionals' attitude in quality of care during childbearing, as well as pointing to the possibility to improve professionals' attitudes with a process-oriented training.

\section{Appendix 1}

The process-oriented training for healthcare professionals.

Definition of the process-oriented training: In order to improve attitudes of health professionals the training was based on evidence, practical skills and reflective processes (both private and professional experiences) in relation to breastfeeding and parental support. To ensure that the healthcare professionals would be ready to meet the demands of their profession they were trained in problem solving, self-reflection, and decision-making (in terms of competence), and their personal qualifications evaluated (Jerlock, Falk \& Severinsson (2003)).

The process-oriented training involved seven days of lectures and its main theme focused on the participants' breastfeeding experiences (both private and professional), breastfeeding attitudes, breastfeeding counselling, and collaboration and communication between antenatal centers and child health centers in line with WHO recommendations". Midwives and postnatal nurses were asked to reflect on different areas relating to breastfeeding support. The training supervisors were chosen to strengthen the process between the healthcare centers and the hospital wards. Both the literature and the lecturers raised parenthood, breast-feeding, relations, attachment, the baby's ability as well as complications around childbearing as well as a common parental education with both midwives and postnatal nurses included. It was the same parental education groups during pregnancy and the babies first year of life. 
The healthcare professionals chose the following topics in order to offer an individualized professional support during childbirth:

- reflections on how breastfeeding occurred in the participants' lives, both private, in education and professional life,

- the woman's physical and mental adaptation to the breastfeeding situation,

- the infant's own power, and senses, both as unborn and as newborn,

- parents relations and parental leave, in a gender and cultural perspective,

- protect, promote, and support breastfeeding and family health,

- parent-infant interaction and

- in history of a global and organizational perspective.

Different themes were treated in each group, these were then reported in the cross-groups. A written summary was made so that everyone could take part of everyone's work. The entire course ended with the professionals at every municipality did their own suggestions on parental education together. Parental education would be implemented by the professionals together during the pregnancy and baby's first year.

Jerlock M, Falk K, Severinsson E. 2003 Academic nursing education guidelines: Tools for bridging the gap between theory, research and practice. Nurs Health Sci 5: 219-228.

\section{Competing interests}

The authors declare that they have no competing interests.

\section{Authors' contributions}

According to ICMJE guidelines, AE have made substantial contributions to conception and design, and acquisition of data analysis and interpretation of data. ST have made acquisition of some of the data analysis and interpretation of data. AE and ST have drafting the manuscript and have given final approval of the version to be published.

\section{Acknowledgements}

This study was supported by the Skaraborg Institute for Research and Development; the School of Health and Education of the University of Skövde; the Primary Care Unit in Skaraborg and the Science Committee, Central Hospital, Skövde; the Strategic Research Programme in Care Sciences and the Board of Research for Health and Caring Sciences, Swedish Research Council, grant nos. K1999-27P-13085-01A and K2001-27P-13085-036, Eva Nissen.

Received: 27 June 2015 Accepted: 19 October 2015

Published online: 26 October 2015

\section{References}

1. Cowan CP, Cowan PA. When partners become parents. The big life change for couples. USA: Lawrence Erlbaum Associates; 2000.

2. Thorstensson S, Hertfelt-Wahn E, Langius-Eklöf A, Ekström A. Evaluation of the Mother-to-Infant relation and feeling scale: Interviews with first-time mothers' for feelings and relation to their baby three days after birth. International Journal of Nursing and Midwifery. 2012;4(1):8-15.
3. Downe S. Toward Salutogenic Birth in the 21st Century. In: Walsh D, Downe S, editors. Essential midwifery practice: intrapartum care. Oxford: WileyBlackwell; 2010.

4. Raphael-Leff J. Psychological processes of childbearing. 4th ed. Anna Freud Centre: Guildford; 2005

5. Hildingsson I, Thomas JE. Women's Perspectives on Maternity Services in Sweden: Processes, Problems and Solutions. Journal of Midwifery and Womens Health. 2007:52(2):126-33.

6. Seefat-van Teeffelen A, Nieuwenhuijze M, Korstjens I. Women want proactive psychosocial support from midwives during transition to motherhood: a qualitative study. Midwifery. 2011;27(1):122-7.

7. Kahn R, Antonucci T. Convoys of the life Course: Attachment, Roles and Social support. In: Lifespan development and behavior, vol. 3. New York: Academic P; 1980. p. 253-86.

8. Cassidy J. The nature of the child's ties. In: Handbook of attachment Theory, research and clinical applications. Ith ed. New York: The Guildford Press; 1999. p. 925.

9. Langford C, Bowsher J, Maloney J, Lillis P. Social support: a conceptual analysis. J Adv Nurs. 1997;25(1):95-100.

10. Oakley A: Giving support in pregnancy; the role of research midwives in a randomized controlled trial chap. 4. In: Midwives, Research and Childbirth. vol. 3. London: Chapman \& Hall; 1994: 30-63.

11. Bäckström C, Hertfelt-Wahn E. Support during labour: first-time fathers' descriptions of requested and received support during the birth of their child. Midwifery. 2011;27(1):67-73.

12. Dahlen $H$, Barclay $L$, Homer $C$. The novice birthing; theorising first time mothers' experiences of birth at home and in hospital in Australia. Midwifery. 2010;26(1):53-63.

13. Lundgren I. Releasing and relieving encounters: experiences of pregnancy and childbirth. Scand J Caring Sci. 2004;18(4):368-75.

14. Lundgren I. Swedish women's experience of childbirth 2 years after birth. Midwifery. 2005;21(4):346-54

15. Ekström A, Nissen E. A Mother's feelings for Her infant are strengthen by excellent breast feeding counseling and continuity of care. Pediatrics. 2006;118(2):309-14.

16. Tarkka M-T, Paunonen M. Social support provided by nurses to recent mothers on a maternity ward. J Adv Nurs. 1996;23(6):1202-6.

17. Thorstensson S, Nissen E, Ekström A. Professional Support in Pregnancy Influence Maternal Relation to and Feelings for the Baby after Cesarean Birth; an Intervention Study. J Nurs Care. 2012;1(3). doi:10.4172/2167-1168.1000112.

18. Renfrew M, McCormick F, Wade A, Quinn B, Dowswell T. Support for healthy breastfeeding mothers with healthy term babies. Cochrane Database Syst Rev. 2012;5.

19. Brown JB, Beckhof C, Bickford J, Stewart M, Freeman TR, Kasperski J. Women and their partners' perception of the Key Roles of the Labor and Delivery Nurse. Clin Nurs Res. 2009;18(4):323-35.

20. Jerlock M, Falk K, Severinsson E. Academic nursing education guidelines: Tool for bridging the gap between theory, research and practice. Nurs health sci. 2003;5(3):219-28.

21. Phillips D, Fawns R, Hayes B. From personal reflection to social positioning: the development of a transformational model of professional education in midwifery. Nurs Inq. 2002;9(4):239-49.

22. Ekström A, Widström A, Nissen E. Process-oriented Training in Breastfeeding Alters Attitudes to Breastfeeding in Health Professionals. Scand J Public Health. 2005;33(6):424-31.

23. Blixt I, Mårtensson L, Ekström A. Process-oriented training in breastfeeding for health professionals decreases women's experiences of breastfeeding challenges. Int Breastfeed J. 2014;9.

24. Ekström A, Abrahamsson H, Eriksson R-M, Mårtensson L. Women's use of nipple shields - their influence on breastfeeding duration after a processoriented education for health professionals. Breastfeed Med. 2014;9.

25. Ekström A, Guttke K, Lenz M, Hertfelt-Wahn E. Long term effects of professional breastfeeding support - An intervention International. J Nursing Midwifery. 2011;3(8):109-17.

26. Ekström A, Kylberg E, Nissen E. A process-oriented breastfeeding training program for health professionals to promote breastfeeding. Breastfeed Med. 2012;7(2):85-92.

27. Ekström A, Nissen E. Process-Oriented Training in Breastfeeding Attitudes and Continuity of Care Improve Mothers Perception of Support. In: Hong PR, editor. Health Education Research Trends. New York: Nova Science Publishers, Inc; 2007. p. 211-25. 
28. Ekström A, Widström A-M, Nissen E. Does continuity of care by well-trained breast feeding counselors improve a mothers perception of support? Birth. 2006;33(2):123-30.

29. Ekström A, Widström A-M, Nissen E. Duration of Breastfeeding in Swedish Primiparous and Multiparous Women. J Hum Lact. 2003;19(2):172-8.

30. Ekström A, Widström A-M, Nissen E. Breastfeeding Support from Partners and Grandmothers: Perceptions of Swedish Women. Birth. 2003;30(4):261-6.

31. Ekström A, Matthiesen A-S, Widström A-M, Nissen E. Breastfeeding attitudes among counselling health professionals. Scand J of Public Health. 2005;33(5):353-9.

32. Polit D, Beck C. Nursing Research. Generating and Assessing Evidence for Nursing Practice, 9th edn. Philadelphia: Lippincott Williams and Wilkins; 2011.

33. Cohen L, Manion L, Morrison K. Research methods in education. 6th ed. New York, USA: Routledge; 2009.

34. Zanna M, Rempel JK. Attitudes, a new look at an old concept. In: Bar-Tal D, Kruglanski A, editors. The social psychology of knowledge. University Press: NY, Cambridge; 1986.

35. Brown J, Beckhof C, Bickford J, Stewart M, Freeman T, Kasperski J. Women and their partners' perception of the Key Roles of the Labor and Delivery Nurse. Clin Nurs Res. 2009;18(4):323-5.

36. Thorstensson S, Ekström A, Lundgren I, Hertfelt Wahn E. Exploring Professional Support Offered by Midwives during Labour: An Observation and Interview Study. Nursing Research and Practice 2012; 648405:10. doi:10.1155/2012/648405.

37. Hupcey J. Clarifying the social theory-research linkage. J adv nurs. 1998;27(6):1231-41.

38. Uvnas-Moberg K, Arn I, Magnusson D. The psychobiology of emotion: the role of the oxytocinergic system. Int J Behav Med. 2005;12(2):59-65.

39. Fisher J, JAstbury J, Smith A. Adverse psychological impact of operative obstetric interventions: a prospective longitudinal study. Aust N Z J Psychiatry. 1997;31:728-38.

40. Garel M, Lelong N, Kaminski M. Follow-up study of psychological consequences of caesarean childbirth. Early Hum Dev. 1988;16(2-3):271-82.

41. Mutryn C. Psychosocial impact of cesarean section on the family; a literature review. Soc Sci Med. 1993;37(10):1271-81.

42. DiMatteo M, Morton S, Lepper H, Damush T, Carney M, Pearson M, et al. Caesarean childbirth and psychosocial outcomes: A meta analysis. Health Psychol. 1996;15:303-14.

43. Rowe-Murray H, Fisher J. Operative intervention in delivery is associated with compromised early mother-infant interaction. Br J Obstet Gynaecol. 2001;108(10):1068-75.

44. Ingram J, Johnsson D, Condon L. The effects of baby friendly initiative training on breastfeeding rates and the breastfeeding attitudes, knowledge and self-efficacy of community health-care staff. Primary Health Care Research \& Development. 2011;12(3):266-75.

45. Hauck Y, Graham-Smith C, Mclnerney J, Kay S. Western Australian women's perceptions of conflicting advice around breast feeding. Midwifery. 2011;27(5):156-62.

46. Bäckström C, Hertfelt-Wahn E, Ekström A. Two sides of breastfeeding support: experiences of women and midwives. Int Breastfeed J. 2010;5:20.

47. Dietrich Leurer M, Misskey E. "Be positive as well as realistic": a qualitative description analysis of information gaps experienced by breastfeeding mothers. Int Breastfeed J. 2015;10:10.

48. Moore E, Coty M-B. Prenatal and postpartum focus groups with primiparas: breastfeeding attitudes, support, barriers, self-efficacy, and intention. J Pediatr Health Care. 2006;20(1):35-46.

49. Haroon S, Das J, Salam R, Imdad A, Bhutta Z. Breastfeeding promotion interventions and breastfeeding practices: a systematic review. BMC Public Health. 2013;1(3):S20.

50. Laanterä S, Pietilä A-M, Ekström A, Pölkki T. Confidence in breastfeeding among pregnant women. West J Nurs Res. 2012;34(7):933-51.

51. Machin D, Campbell M. Design of Studies for Medical Research. John Wiley \& Sons Ltd: Chichester, England, Great Britain; 2005.

\section{Submit your next manuscript to BioMed Central and take full advantage of:}

- Convenient online submission

- Thorough peer review

- No space constraints or color figure charges

- Immediate publication on acceptance

- Inclusion in PubMed, CAS, Scopus and Google Scholar

- Research which is freely available for redistribution

Submit your manuscript at www.biomedcentral.com/submit 